\title{
Pheromone-dependent phosphorylation of the yeast STE12 protein correlates with transcriptional activation
}

\author{
Ok-kyu Song, ${ }^{1}$ Joseph W. Dolan, ${ }^{1}$ Yi-lu O. Yuan, ${ }^{2}$ and Stanley Fields ${ }^{1}$ \\ ${ }^{1}$ Department of Microbiology, ${ }^{2}$ Program in Genetics, State University of New York at Stony Brook, Stony Brook, New York \\ 11794 USA
}

\begin{abstract}
Haploid a and $\alpha$ cells of yeast respond to the pheromones $\alpha$ - and a-factor, respectively, by increasing the transcription of many genes whose products are essential for mating. The STE12 protein acts in this process by binding to the DNA sequence that mediates the increased transcription of pheromone-responsive genes. We show here that a hybrid protein containing STE12 fused to the DNA-binding domain of GAL4 can activate transcription of a reporter gene containing GAL4-binding sites but only after treatment of cells with pheromone. Thus, STE12 alone, when bound to DNA, is sufficient to mediate pheromone-induced transcription. By constructing hybrids of different STE12 regions with the GAL4 domain, we map the domain of STE12 necessary for this activation to the central third of the protein. Upon $\alpha$-factor treatment, the hybrid of GAL4 with the complete STE12 sequence is rapidly phosphorylated, with kinetics consistent with the observed transcriptional induction of pheromone-responsive genes. The domain of STE12 necessary for this phosphorylation correlates with that involved in transcriptional activation. We propose that induction of pheromone-responsive genes is mediated by phosphorylation of STE12 to alter its activation function but not its DNA-binding ability.
\end{abstract}

[Key Words: Yeast; STE12 protein; pheromone response; transcription; DNA-binding protein; phosphorylation] Received November 2, 1990; revised version accepted February 15, 1991.

Changes in gene transcription are a common response of cells to environmental stimuli; in several cases, these changes are mediated by the modification of site-specific DNA-binding transcription factors (Mitchell and Tiian 1989). The response to pheromone of the yeast Saccharomyces cerevisiae provides a genetically tractable system to study signal transduction processes resulting in transcriptional effects. Binding of the appropriate pheromone leads to increases in cell-type-specific transcription, an essential requirement for mating (for review, see Herskowitz 1989; Fields 1990). This transcriptional induction appears to be mediated by the STE12 protein, which binds to the pheromone response element (PRE) present in the upstream region of many inducible genes (Dolan et al. 1989; Errede and Ammerer 1989).

The response of a cells to $\alpha$-factor or $\alpha$ cells to a-factor involves a pathway that includes the pheromone receptors; a tripartite G protein encoded by the GPA1, STE4, and STE18 genes (Dietzel and Kurjan 1987; Miyajima et al. 1987; Jahng et al. 1988; Whiteway et al. 1989); the STE5 protein; and the STE7, STE11, and FUS3 proteins, whose predicted sequences are related to protein kinases (Teague et al. 1986; Elion et al. 1990; Rhodes et al. 1990). Mutation of any of the genes that act positively in the response pathway $(S T E 4, S T E 5, S T E 7, S T E 11, S T E 12$, and
STE18) leads to a loss of both constitutive and inducible cell-type-specific transcription (Hartwell 1980; Fields and Herskowitz 1985; Hartig et al. 1986; Fields et al. 1988; Whiteway et al. 1989). The effect of these mutations suggests that $\mathrm{G}$ protein dissociation occurs at a low level in the absence of pheromone, leading to the production of a constitutive signal that is necessary for the uninduced level of transcription. Binding of pheromone is postulated to lead to increased dissociation of the $G$ protein, triggering induced transcription.

As the protein in this pathway capable of binding to the PRE, STE12 is a likely target for activating transcription in response to pheromone. In addition, overproduction of STE12 results in higher levels of uninduced celltype-specific transcription, even in cells carrying mutations in the response pathway (Dolan and Fields 1990). Combined with the loss of uninduced transcription in ste mutants, these results suggest a model of STE12 function in which STE12 is constitutively modified by the response pathway to function in this uninduced transcription and is further modified as a consequence of pheromone binding to function in induced transcription.

To analyze further the role of STE12 in this induction process, we have characterized biochemical changes in the protein that occur upon treatment of cells with pher- 
omone. We find that STE12 is rapidly phosphorylated in response to the binding of pheromone and that this phosphorylation correlates with the enhanced ability of STE12 to act in transcription. These data are consistent with a model that pheromone treatment leads to transcriptional induction by modifying the STE 12 protein, making it a more potent transcriptional activator.

\section{Results}

\section{Pheromone-dependent transcriptional activation by} GAL4-STE12 fusion proteins

In regulating cell-type-specific transcription, the STE 12 protein acts cooperatively with several proteins that bind to other DNA sequences; in addition, STE12 is not the only protein capable of binding to the PRE (F. Gimble and J. Thorner, pers. comm.). We wished to analyze the transcriptional role of STE12 in the absence of these other activities and, therefore, made use of a strategy employing hybrid proteins. In this approach, a heterologous DNA-binding domain that is unable to activate transcription is fused to a test protein. The hybrid thus generated is then assayed for its ability to activate transcription of a reporter gene containing a binding site for the heterologous DNA-binding domain. For our purposes, we used the amino-terminal 147 amino acids of the GAL4 protein, which bind to the upstream activation sequence $\left(\mathrm{UAS}_{\mathrm{G}}\right)$ present in the regulatory region of genes for galactose metabolism (Keegan et al. 1986). This domain alone produces no transcription of a GAL1-lacZ gene activated by $\mathrm{UAS}_{\mathrm{G}}$ (Keegan et al. 1986).

A hybrid gene was generated that encodes the entire STE12 sequence (688 amino acids) fused to the GAL4 DNA-binding domain and whose expression is under the control of the strong $A D H 1$ promoter. This hybrid gene, carried on a multicopy plasmid, was introduced into a yeast a strain deleted for GAL4 and containing a GAL1lac $Z$ gene. The presence of this hybrid protein resulted in approximately the same very low level of GAL1-lacZ transcription as did the GAL4 DNA-binding domain itself (Fig. 1, lines a and b). However, addition of $\alpha$-factor to cells carrying this hybrid led to a sixfold increase in $\beta$-galactosidase activity (Fig. 1, line b). This result indicates, first, that the full-length STE12 protein can function as a transcriptional activator, but only after pheromone treatment. Thus, we have effectively converted the $\mathrm{UAS}_{\mathrm{G}}$ into a PRE, demonstrating that STE12 is sufficient for pheromone-responsive transcription, independent of other DNA-binding proteins. Second, this result indicates that even after pheromone treatment, the fulllength hybrid is not a potent activator, as the full-length GAL4 protein produces $>200$-fold more GAL1-lacZ transcription (Fig. 1, line h).

To define the region of the STE 12 protein responsible for this transcriptional induction in response to pheromone, we constructed two carboxy-terminal and two amino-terminal deletions of the STE12-coding sequence fused to the GAL4 DNA-binding domain (Fig. 1). GAL4STE12 $2_{(1-473)}$ (line c) and GAL4-STE12 ${ }_{(214-688)}$ (line e) both led to pheromone-dependent transcriptional activity. However, GAL4-STE12 $2_{(1-215)}$ (line d) and GAL4STE $12_{(472-688)}$ (line f) failed to activate: $\beta$-Galactosidase activity of cells carrying these fusion proteins was low and not stimulated by $\alpha$-factor treatment. These results demonstrate that neither the amino-terminal 213 nor the carboxy-terminal 215 amino acids of STE12 are necessary for pheromone-dependent transcriptional activity. To test whether the sequence between these two deletion endpoints is sufficient for this activity, we constructed GAL4-STE12 2 14-473). This fusion protein caused a high level of transcription in untreated cells, and this level was only minimally pheromone responsive (line g). One explanation for this result is that the central region of STE 12 contains a transcriptional activating sequence that lies exposed to the transcriptional machinery in this fusion but not in the larger fusions. The presence of pheromone would then be required for
Figure 1. Transcriptional activation by GAL4-STE12 hybrid proteins. The GAL4 domain is indicated by the shaded region, and the STE 12 domain by the open region. The hybrids were transformed into strain YM709::171, and $\beta$-galactosidase activity was assayed either without treatment or after $2 \mathrm{hr}$ in $\alpha$-factor. Activity is expressed in Miller units (Miller 1972).

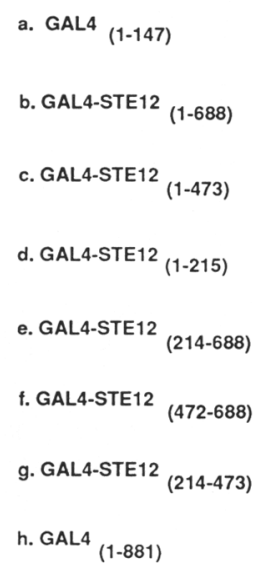


the exposure of this activating domain in the larger fusions.

Another factor that may contribute to the low levels of GAL1-lacZ transcription produced by the fusions carrying large regions of STE12 is that these proteins have additional functions. The amino-terminal 215 amino acids of STE12 are sufficient for specific DNA binding (Y.O. Yuan and S. Fields, unpubl.), and reduced transcriptional activation by fusion proteins containing more than one DNA-binding domain has been observed previously (Weston and Bishop 1989). Thus, any fusion proteins carrying the first 215 amino acids of STE12 may not only bind to $\mathrm{UAS}_{\mathrm{G}}$ by virtue of the GAL4 DNAbinding domain but also to PRE sites by virtue of the STE12 domain. As a test of this possibility, we assayed whether the fusion proteins could complement a ste12 mutation (Fig. 2). Both GAL4-STE12 $(1-688)$ and GAL4 STE12 $1(-473)$ restored mating ability, indicating that these two fusion proteins could also act in cell-type-specific transcription. Comparison of the activity of GAL4 STE12 $214-688)$ and GAL4-STE12 $2_{(214-473)}$ shows that the carboxy-terminal region of STE12 also has a negative effect on GAL1-lacZ transcription. The region from amino acids 470 to 688 appears to interact with the MCM1 protein (Errede and Ammerer 1989), and this interaction may affect the ability of the GAL4

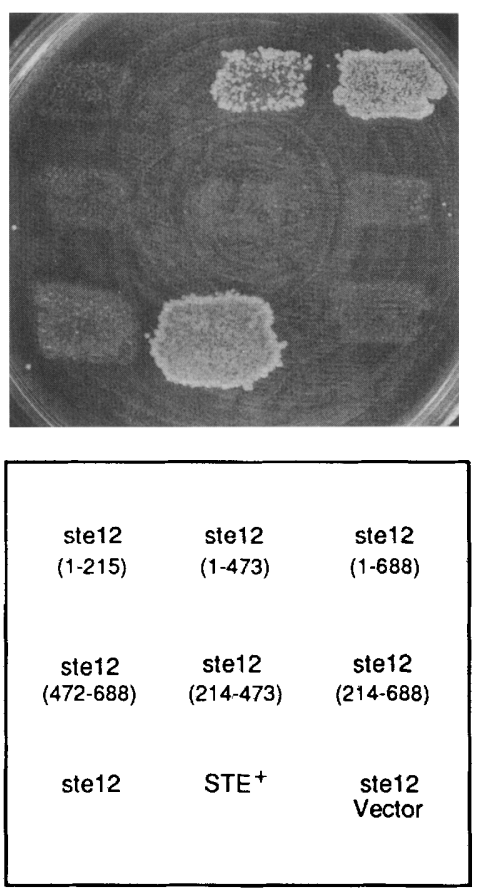

Figure 2. Mating assay of strains producing GAL4-STE12 hybrid proteins. Patches of an a ste12 strain (430) containing different plasmids were replica-plated onto an SD-minimal plate spread with an $\alpha$ strain, such that ability to mate is indicated by the growth of a prototrophic diploid patch. Numbers in parentheses represent the STE12 residues present in the GAL4STE12 hybrids. The vector is the plasmid carrying the GAL4 DNA-binding domain alone, and the $\mathrm{STE}^{+}$strain is isogenic to strain 430 but with the wild-type STE12 allele.
STE12 $214-688)$ hybrid to act at $\mathrm{UAS}_{\mathrm{G}}$. Alternatively, the amino- or carboxy-terminal region may somehow mask an internal transcriptional activating region.

Apart from the pheromones and receptors, the pheromone-responsive transduction pathway appears to use the same components in both a and $\alpha$ cells (Bender and Sprague 1986; Nakayama et al. 1987). a-Factor treatment of $\alpha$ cells carrying the GAL4-STE12 fusion proteins led to the same pattern of transcriptional induction as observed with $\alpha$-factor treatment of a cells (data not shown).

The STE12 protein is phosphorylated in response to pheromone

The rapid pheromone induction of cell-type-specific transcription occurs independently of new protein synthesis (Hagen and Sprague 1984). This result, combined with the demonstration that STE12 binds to the PRE (Dolan et al. 1989; Errede and Ammerer 1989) and is a pheromone-dependent transcriptional activator, suggests that the STE12 protein itself may be a target for a pheromone-induced post-translational modification. To test this idea, we generated polyclonal antiserum to the amino-terminal 215 amino acids of STE12 and used it to immunoprecipitate STE12 from ${ }^{35}$ S-labeled yeast extracts (Fig. 3). The anti-STE12 serum did not detect any specific proteins in an extract from cells containing the control vector encoding the GAL4 DNA-binding domain (lane 1), indicating that the level of chromosomally encoded wild-type STE12 protein is too low to be detected with this assay. However, the antibody detected a protein with an apparent molecular mass of $133 \mathrm{kD}$ in an extract of cells containing GAL4-STE12 ${ }_{(1-688)}$ (lane 3). Chromosomally encoded STE12 can be detected by immunoprecipitation of an extract from vector-containing cells treated with $\alpha$-factor (lane 2). This protein migrates at the approximate position of in vitro-translated STE12 (not shown). STE12 transcription is induced severalfold by pheromone (J.W. Dolan and S. Fields, unpubl.), and this induction may at least partially account for the ability to detect the endogenous protein from pheromone-treated cells. Extracts of cells carrying GAL4STE12 $2_{(1-688)}$ treated with $\alpha$-factor also showed this level of endogenous STE12 protein (lane 4). The GAL4STE12 $11-688)$ fusion protein from $\alpha$-factor-treated cells migrated slightly more slowly and more diffusely than the fusion protein from untreated cells (lane 4).

To determine whether the altered mobility of the fusion protein from $\alpha$-factor-treated cells is due to phosphorylation, we treated ${ }^{35} \mathrm{~S}$-labeled immunoprecipitates with potato acid phosphatase. As shown in Figure 4, pheromone treatment led to a characteristic shift in migration of the fusion protein (cf. lanes 1 and 2); but after incubation with phosphatase (lane 3 ), the protein migrated with a mobility characteristic of that from cells not treated with $\alpha$-factor. Incubation with phosphatase in the presence of phosphatase inhibitors (Verjee 1969) did not affect the rate of migration, and the fusion protein continued to exhibit the slower electrophoretic mo- 


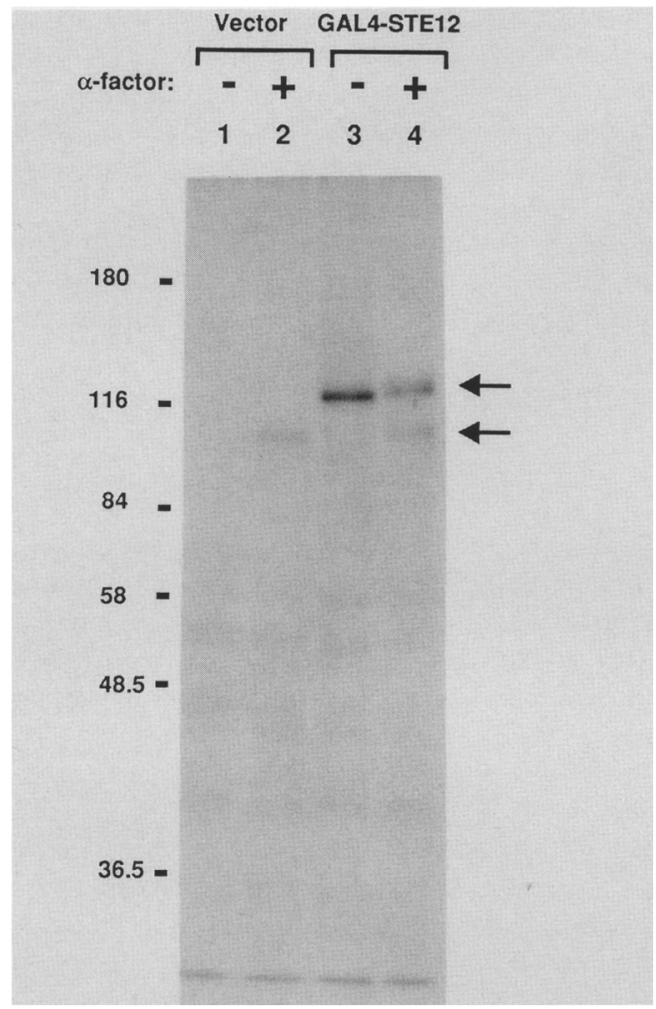

Figure 3. The immunoprecipitation of STE 12 and GAL4 STE12 $2_{(1-688)}$ from cells grown in the absence or presence of $\alpha$-factor. The cells contained either the vector (GAL4 DNAbinding domain alone) or the GAL4-STE12 fusion. Equivalent amounts of ${ }^{35} \mathrm{~S}$-labeled protein were immunoprecipitated with an antibody to STE12, and the precipitates were fractionated by SDS-polyacrylamide gel. Molecular masses of standards are indicated in kilodaltons. The upper arrow indicates GAL4STE12; the lower arrow indicates the native STE12.

bility (lane 4). Thus, the effect of the phosphatase treatment was the specific removal of phosphate groups rather than the action of contaminating activities such as proteases. The alterations in mobility of the fusion protein are reflected in changes in STE12 encoded by the chromosomal copy of the gene (lanes 2-4), confirming the relevance of the changes seen more clearly with the fusion protein.

In several experiments it was clear that the fusion protein from untreated cells migrated as a very closely spaced doublet (lane 5). To determine whether this upper band is due to constitutive phosphorylation of GAL4 STE12 $2_{(1-688)}$, we added phosphatase to immunoprecipitates from cells not treated with $\alpha$-factor. Phosphatase treatment caused the upper band of the fusion protein doublet to disappear (lane 6). Thus, the fusion protein, as observed by ${ }^{35}$ S-labeling, exists in three states: an unphosphorylated form, a pheromone-independent phosphorylated form, and one or more pheromone-dependent phosphorylated forms.

To analyze directly the level of STE12 phosphorylation, we labeled cells with $\left[{ }^{32} \mathrm{P}\right]$ orthophosphate (Fig. 5). As was the case with the ${ }^{35} \mathrm{~S}$-labeled cells, anti-STE12 antiserum failed to immunoprecipitate a specific protein from lysates of ${ }^{32} \mathrm{P}$-labeled cells expressing only the GAL4 DNA-binding domain (lanes 1 and 2), but it could detect the GAL4-STE12 $2_{(1-688)}$ fusion protein (lanes 3 and 4). Treatment of cells with $\alpha$-factor caused an increase in the level of labeling of the fusion protein and also the appearance of additional, more slowly migrating forms of the fusion protein (lanes 3 and 4). The ${ }^{32}$ P-labeling indicates the constitutive presence of more slowly migrating forms which, with ${ }^{35}$ S-labeling, are only detected after pheromone treatment (cf. lanes 3 and 4 with lanes 5 and 6). On the basis of the ${ }^{32} \mathrm{P}$-labeling intensity and slower migration, these forms likely represent more highly phosphorylated forms of the fusion protein.

\section{Pheromone-dependent phosphorylation of STE12 is rapid and independent of protein synthesis}

We assayed whether the kinetics of STE12 phosphorylation following pheromone treatment correlate with the transcriptional induction caused by pheromone. Cells were ${ }^{35} \mathrm{~S}$-labeled and treated with $\alpha$-factor for increasing time (Fig. 6A). The pheromone-induced phosphorylation, observed here as a more slowly migrating species, could be detected as early as $2.5 \mathrm{~min}$ after the addition of pheromone and appears to be largely complete by $5 \mathrm{~min}$ (Fig. $6 \mathrm{~A})$. This rapid modification is consistent with the effect of pheromone on transcription, in which increases in RNA levels are observed within minutes of pheromone

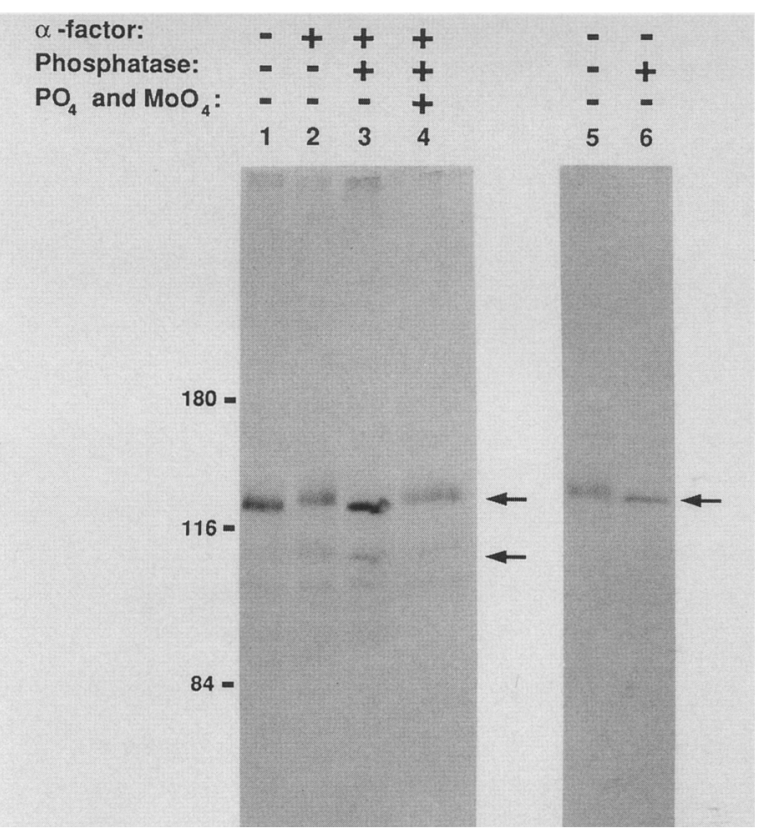

Figure 4. $\alpha$-Factor leads to phosphorylation of GAL4-STE12. ${ }^{35} \mathrm{~S}$-Labeled cells carrying GAL4-STE $12_{(1-688)}$ were untreated or treated with $\alpha$-factor as indicated. Cell extracts were immunoprecipitated as in Fig. 3, and the precipitates were treated with potato acid phosphatase or phosphatase plus inhibitors $\left\langle\mathrm{PO}_{4}\right.$ and $\mathrm{MoO}_{4}$ ) as indicated. (Lanes 1-4) The upper arrow indicates GAL4-STE12; the lower arrow indicates the native STE12. (Lanes 5 and 6) The arrow indicates GAL4-STE12. 


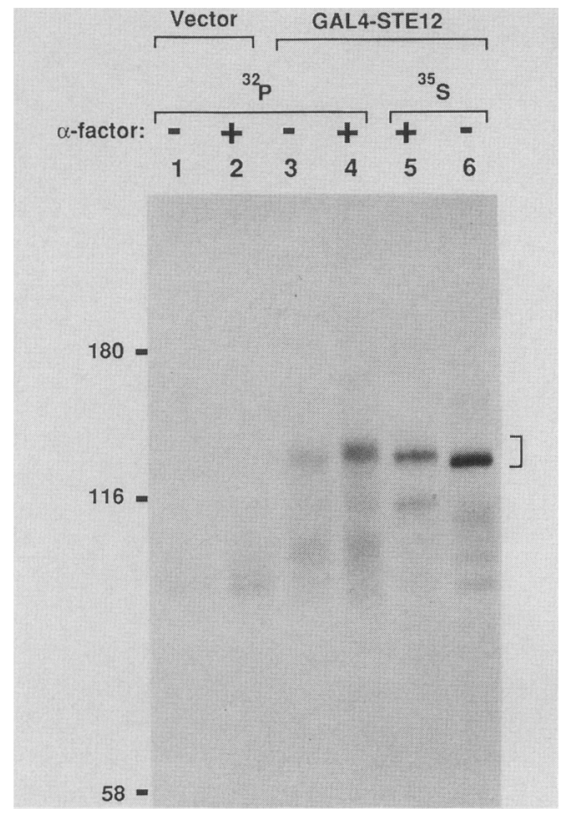

Figure 5. Comparison of ${ }^{32} \mathrm{P}$ - and ${ }^{35} \mathrm{~S}$-labeled GAL4-STE12. Cells carrying GAL4-STE12 $2_{(1-688)}$ were labeled with $\left[{ }^{32} \mathrm{P}\right]$ orthophosphate or ${ }^{35} \mathrm{~S}$-labeled amino acids and left untreated or treated with $\alpha$-factor, as indicated. Cell extracts were immunoprecipitated as in Fig. 3 , and the immunoprecipitates were fractionated on a $6 \%$ gel. The bracket indicates the GAL4-STE12 forms.

treatment (Hagen and Sprague 1984; Stetler and Thorner 1984; McCaffrey et al. 1987).

Pheromone-dependent transcriptional induction is insensitive to the effects of the protein synthesis inhibitor cycloheximide (Hagen and Sprague 1984), suggesting that induction involves modification of pre-existing protein. However, pheromone treatment results in the rapid accumulation of new transcripts and proteins. It is therefore possible that the STE12-modifying activity is induced by pheromone and that STE12 phosphorylation is a secondary response to pheromone not directly related to a role for STE12 in induction of transcription. We labeled cells for $5 \mathrm{~min}$ with ${ }^{35} \mathrm{~S}$-labeled amino acids, followed by treatment with $100 \mu \mathrm{g} / \mathrm{ml}$ of cycloheximide for $5 \mathrm{~min}$, which was sufficient to eliminate any further incorporation of label into trichloroacetic acid (TCA)precipitable protein (data not shown). Addition of $\alpha$-factor to the cycloheximide-treated culture still resulted in the appearance of the phosphorylated forms of STE12 (Fig. 6B), indicating that synthesis of new proteins is not required for STE12 modification. The rapid appearance and cycloheximide insensitivity of the phosphorylated forms of STE12 are consistent with phosphorylation playing a role in transcriptional induction and not in a later process such as recovery or adaptation.

\section{Correlation between transcriptional activation and phosphorylation}

In addition to GAL4-STE12 $2_{(1-688)}$ other fusion proteins were also capable of enhanced GAL1-lacZ transcription following pheromone treatment (Fig. 1). To examine whether the induced transcriptional activity correlated with phosphorylation following $\alpha$-factor treatment, we immunoprecipitated extracts from cells containing certain GAL4-STE12 fusion proteins (Fig. 7). Like GAL4 STE12 $2_{(1-688)}$ (lanes 1 and 2), GAL4-STE 12 $2_{(1-473)}$ also showed pheromone-dependent phosphorylation (lanes 3 and 4). However, GAL4-STE12 $2_{(1-215)}$ (lanes 7 and 8) and the GAL4 DNA-binding domain alone (lanes 9 and 10) migrated the same after pheromone treatment as without treatment. There is thus a good correlation between the ability of these fusion proteins to activate transcription following pheromone treatment and their ability to be phosphorylated by the response pathway. The GAL4STE12 $214-473)$ fusion, after treatment of cells with pheromone, showed a small increase in the amount of protein present as a slightly slower migrating species (lanes 5 and 6). The relatively minor biochemical change in this fusion protein in response to pheromone correlates with the ability of this protein to activate transcription only 1.6-fold better after pheromone treatment (Fig. 1). The lack of a pronounced pheromone-dependent shift observed with GAL4-STE12 $2_{(214-473)}$ may be due to its high level of phosphorylation in the absence of pheromone, as incubation with phosphatase indicated that all of the GAL4-STE12 $2_{(214-473)}$ protein present in cells not treated with pheromone is phosphorylated (data not shown). Alternatively, there may be phosphorylation that requires, but occurs outside of, the region between amino acids 214 and 473.

\section{Pheromone treatment does not significantly alter the DNA-binding activity of STE12}

The previous experiments examined the properties of fusion proteins containing the DNA-binding domain of a heterologous protein that is not responsive to pheromone treatment. We also tested directly whether pheromone treatment affects the DNA-binding ability of the native STE12 protein (Fig. 8). Cells overproducing STE12 were treated with $\alpha$-factor, followed by preparation of extracts for gel-mobility shift assays. Treatment of cells with $\alpha$-factor (lane 3 ) failed to increase significantly for decrease) the ability of STE12 to bind to DNA in vitro. This result is therefore consistent with pheromone treatment affecting some aspect of STE12 function other than DNA binding. We cannot rule out the possiblity, however, that in vivo, the DNA-binding ability is altered, for example, by a pheromone-dependent alteration in a DNA-binding factor with which STE12 must interact. Such a pheromone-dependent effect might be detectable only with DNA probes containing certain STE12-binding sites.

\section{Discussion}

The STE12 protein is required for both constitutive and pheromone-induced levels of cell-type-specific transcription and binds to the DNA sequence that mediates transcriptional induction. We show here that a fusion pro- 
Figure 6. Kinetics of GAL4-STE12 phosphorylation and evidence that protein synthesis is not required for the phosphorylation. (A) Cells carrying GAL4-STE12 $2_{(1-688)}$ were labeled with ${ }^{35}$ S-labeled amino acids and treated with $\alpha$-factor. Aliquots were removed at the times indicated and immunoprecipitated with antibody to STE12. (B) Cells carrying GAL4-STE12 $2_{\{1-688\}}$ were labeled with ${ }^{35} \mathrm{~S}$-labeled amino acids for $5 \mathrm{~min}$ and where indicated, treated with cycloheximide for $5 \mathrm{~min}$. $\alpha$-Factor was then added (lanes 2 and 4 ) for an additional $5 \mathrm{~min}$, after which all cultures were lysed and immunoprecipitated with antibody to STE12.
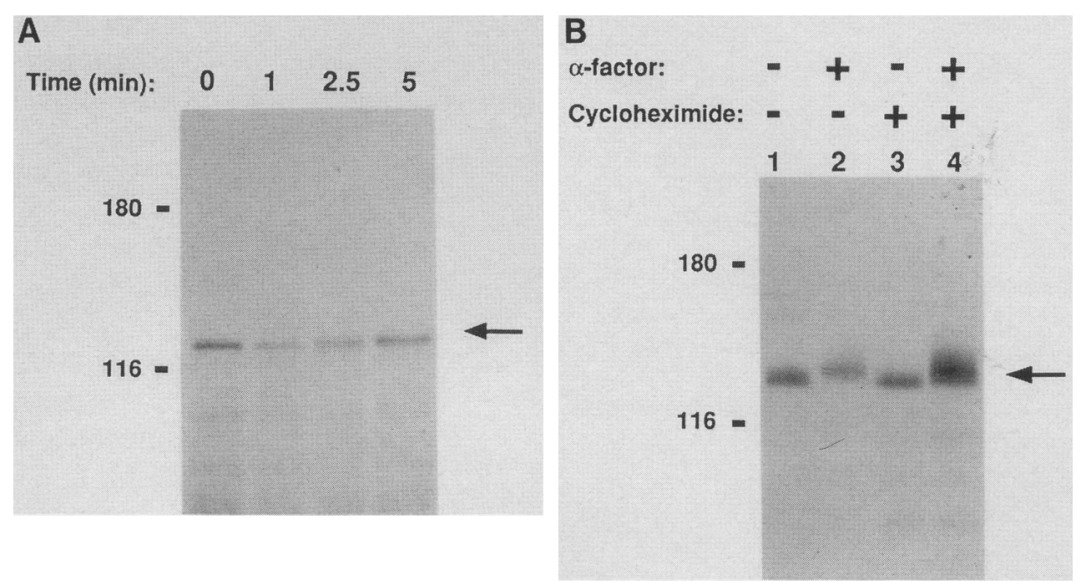

tein of the GAL4 DNA-binding domain and STE12 is capable of activating transcription of a gene that carries GAL4-binding sites but only after the cells carrying the fusion have been treated with pheromone. This result establishes that STE12 alone, when bound to DNA, is sufficient to mediate pheromone-induced transcription. STE12 itself could activate this induced transcription or it may bring other transcription factors to the DNA via protein-protein contacts. The GAL4-STE12 fusion protein also becomes phosphorylated after pheromone treatment. The pheromone-induced phosphorylation of STE12 is rapid and independent of protein synthesis, with kinetics that are similar to the transcriptional in- duction of cell-type-specific genes by pheromone. Fusion proteins capable of pheromone-induced transcription also show pheromone-induced phosphorylation. Our results are therefore consistent with a model that pheromone treatment leads to transcriptional induction by increasing the phosphorylation and consequent activity of STE12. In addition, pheromone treatment leads to increased transcription of the STE12 gene itself, and this autoregulation may amplify the pheromone response.

STE 12 resembles other transcriptional activators that respond to an environmental signal by phosphorylation. For example, the GAL4 protein has highly phosphorylated forms correlating with growth in media that induce

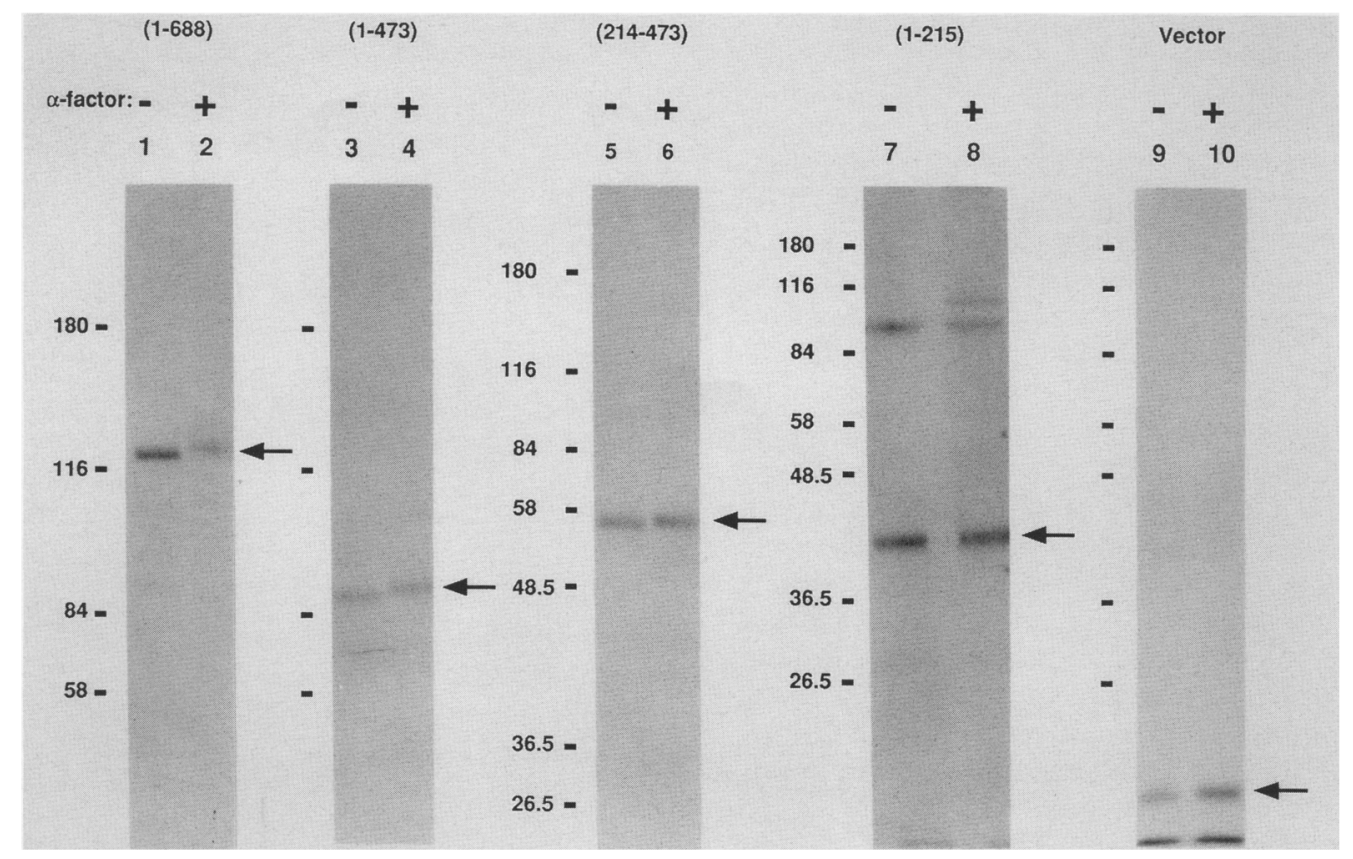

Figure 7. Pheromone-dependent phosphorylation of hybrids carrying different regions of STE12. Numbers in parentheses indicate the region of STE12 fused to the GAL4 DNA-binding domain; vector is the GAL4 domain only. Cultures were ${ }^{35} \mathrm{~S}$-labeled, and half of each culture was treated with $\alpha$-factor as indicated. Extracts were treated with antibody to STE12 (lanes $1-4,7$, and 8 ) or to GAL4 (lanes $5,6,9$, and 10). Immunoprecipitates were electrophoresed on 6\% (lanes 1-4) or 8\% (lanes 5-10) SDS-polyacrylamide gels. Molecular weight markers for lanes 1-4 are to the left of lane 1, and for lanes 7-10 to the left of lane 7 . Arrows indicate the positions of the hybrid proteins. 


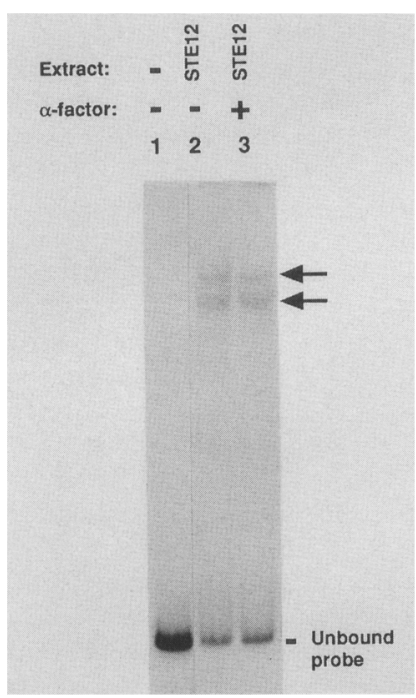

Figure 8. DNA-binding activity of STE12 is unaffected by $\alpha$-factor treatment. STE12 DNA-binding activity was detected by a gel mobility-shift assay using as probe a fragment of the $M F A 2$ gene that contains two PRE sequences and produces two STE12-dependent complexes (arrows). (Lane 1) No extract; (lanes 2 and 3) extract from cells containing a high-copy plasmid with the STE12 gene. Half of the culture was treated with $\alpha$-factor for $10 \mathrm{~min}$ (lane 3 ).

transcription of the GAL genes (Mylin et al. 1989, 1990). Several different mechanisms may operate to alter the activity of transcription factors following phosphorylation. (1) The transcriptional activation domains of certain factors, for example, the yeast GAL4 and GCN4 proteins (Hope and Struhl 1986; Ma and Ptashne 1987), are acidic, and mutations that increase the acidity of the domain frequently enhance the ability of the factor to activate transcription (Gill and Ptashne 1987). Thus, phosphorylation of the activation domain may represent a controllable means of increasing the acidity of an activation domain in response to changes in conditions. Such a mechanism has been proposed for the yeast heatshock factor (HSF), which is more active in transcription at higher temperatures and shows heat-induced phosphorylation (Sorger et al. 1987; Sorger and Pelham 1988). (2) In some cases, the DNA-binding ability of a protein is altered by phosphorylation. For example, the DNA-binding activity of serum response factor (SRF) is dramatically increased by casein kinase II phosphorylation (Manak et al. 1990). The affinity of SV40 large T antigen for the viral origin of replication is increased by phosphorylation of a single threonine residue (McVey et al. 1989), although this modification has been shown to affect replication and not transcription. (3) Phosphorylation may cause conformational changes in the structure of the activator. For the cAMP response element-binding protein (CREB), phosphorylation by protein kinase $A$ appears to result in an allosteric change that allows a distal site to interact with the transcription apparatus (Yamamoto et al. 1990). (4) Transcriptional activators may be bound to inhibitory components, and these interac- tions may be regulated by phosphorylation. Phosphorylation on the inhibitory factor IкB appears to dissociate it from the transcription factor $\mathrm{NF \kappa B}$, which can then translocate to the nucleus and activate transcription (Ghosh and Baltimore 1990). (5) Phosphorylation of the transcription factor itself may influence its entry into the nucleus. The yeast SWI5 protein enters the nucleus in early $G_{1}$, and this phenomenon may be mediated by cell-cycle-regulated phosphorylation (Nasmyth et al. 1990).

Our results suggest that the efficacy of the STE12 activation domain is increased following pheromoneinduced phosphorylation. Nuclear localization, dimerization, and specific DNA binding of the GAL4-STE12 fusion proteins can all be accomplished by the GAL4 domain, which is highly unlikely to vary in response to pheromone. In this regard, the GAL4 DNA-binding domain does not exhibit altered electrophoretic mobility following pheromone treatment, nor does the full-length GAL4 activate more transcription after pheromone treatment. Our results also indicate that the native STE12 protein present in extracts from both untreated and pheromone-treated cells binds to DNA with similar affinity. Phosphorylation of STE12 may make it a better transcriptional activator because of its increased acidity. Alternatively, phosphorylation may change the conformation of the protein such that an activating region becomes exposed to the transcription machinery. The presence of such a region is suggested by the results with GAL4-STE12 (214-473), which is a potent activator even in the absence of pheromone. In the full-length protein this activation domain may be masked by the amino or carboxyl terminus until pheromone-induced phosphorylation occurs. The sequence of STE12 indicates that the region from residue 214 to 473 is highly acidic (net charge of -13 ) and relatively rich in serine, threonine, and tyrosine residues $(20 \%)$, as well as proline residues $(13 \%)$. Abundance of these four amino acids has been noted in other transcriptional activation domains (Mermod et al. 1989; Theill et al. 1989).

On the basis of our results with the GAL4-STE12 fusions, the STE12 moiety may be either unphosphorylated, phosphorylated in a pheromone-independent manner, or phosphorylated in a pheromone-dependent manner. In the absence of pheromone, the GAL4STE $12_{(1-688)}$ fusion is almost completely inactive for transcription of GAL1-lacZ. This observation is consistent with the low level of constitutive expression of genes such as FUS1 (McCaffrey et al. 1987; Trueheart et al. 1987), whose regulatory regions contain multiple copies of the PRE and no strong UAS elements. Although approximately half of the population of the STE12 fusion protein is phosphorylated in the absence of pheromone (on the basis of ${ }^{35} \mathrm{~S}$ labeling), this modification does not appear to provide significant transcriptional activity. It may be that the forms that are apparently more highly phosphorylated (and in very low abundance), seen only by ${ }^{32} \mathrm{P}$-labeling, are active in transcription and allow the fusion protein to complement a ste12 deletion. Pheromone treatment appears to lead to at least two modified 
forms of STE12, suggesting multiple phosphorylations. Modulation of the extent of pheromone-induced phosphorylation may allow the cell to respond to different levels of pheromone with different increases in transcription. The pheromone response is not an allor-nothing phenomenon, as different aspects of the response require different concentrations of pheromone (Moore 1983). It is possible that different protein kinases are responsible for the phosphorylations observed in the absence or presence of pheromone, or that the same kinase(s) become more active after pheromone treatment. Some of the phosphorylations occurring in the absence of pheromone may be dependent on a functional pheromone response pathway, such that mutations in this pathway decrease constitutive transcription through their effect on STE12 phosphorylation.

The pheromone-responsive transcriptional activator STE12 is another member of the growing set of transcription factors whose activities are modulated by phosphorylation. Phosphorylation represents a rapid and reversible means of altering the activity of a protein in response to changing conditions, such as an encounter with a cell of the opposite mating type. For STE12 it should be possible to determine which component(s) of the pheromone response pathway catalyze these modifications and, ultimately, to assay the various forms of the protein in an in vitro transcription system. It will also be of interest to characterize the changes STE 12 undergoes later in the pheromone response, when transcriptional activity returns to uninduced levels, and as cells adapt for growth in the continuous presence of pheromone.

\section{Materials and methods}

Yeast strains and growth media

Yeast strains used were YM709::171 [MATa ura3-52 his3-200 met trp1 can1 gal4D gal80D GAL1-lacZ(URA3); Ma and Ptashne 1987), W303-1a (MATa ade2-1 trp1-1 can1-100 leu23,112 his3-11,15 ura3-1; from R. Rothstein), 430 (isogenic to W303-1a except ste12::URA3), and EG123 (MATa trp1 leu2 ura3 his4 can1); (Siliciano and Tatchell 1984). Media used were YEP, synthetic (S) (Sherman et al. 1986), and modified Wickerham's (Wickerham 1946), in which the sulfates and phosphates were replaced by chlorides. Carbon sources were $2 \%$ glucose (YEPD and SD), $4 \%$ raffinose (SRaf), or $2 \%$ galactose $/ 2 \%$ glycerol/2\% ethanol (SGGE). Synthetic media were supplemented with amino acids and nucleosides (Sherman et al. 1986). To maintain plasmids with selectable markers, the media were supplemented with all but the indicated component(s) (e.g., SDhistidine).

\section{Plasmids}

Plasmid pMA424 contains the GAL4 DNA-binding domain (amino acids 1-147) under the control of the $A D H 1$ promoter (Ma and Ptashne 1987); pCL1 contains the full-length GAL4 protein under the control of this promoter (Fields and Song 1989|. To construct pGAL4-STE12 ${ }_{1-688}$, the STE12-coding region was fused in-frame to the GAL4 DNA-binding domain of pMA424 as an EcoRI cassette. This cassette was constructed as follows. An NdeI site within the coding region was eliminated, and a new NdeI site was created at the translation start site by oligonucleotide mutagenesis, generating pY6. An EcoRI site was then created at the translation start site by insertion of an NdeI-EcoRI linker, generating pYO8. To construct pGAL4STE12 $1-473$, an EcoRI-BamHI subfragment of the EcoRI cassette of pYO8 was cloned into pMA424. To construct pGAL4STE12 ${ }_{1-215}$, an EcoRI-XbaI subfragment of the EcoRI cassette of pYO8 was first cloned into pUC18 and then transferred into pMA424. pGAL4-STE12 214-688 was constructed by first digesting pY6 with $\mathrm{XbaI}$ and religating, removing a $0.6-\mathrm{kb} \mathrm{XbaI}$ fragment and inserting a $X b a I-E c o R I$ linker into the $X b a I$ site, generating pYY3. The resultant EcoRI fragment was then cloned into pMA424. pGAL4-STE12/214473 was constructed by cloning an EcoRI-BamHI subfragment of pYY3 into pMA424. To construct pGAL4-STE12 $472-688$, the EcoRI-HindIII fragment from pY08 was cloned into pUC19 digested with EcoRI and HindIII and a HindIII-BglII linker was inserted to yield pYRl. The BamHI-BglII fragment of pYRl was cloned into the BamHI site of pUC9, and a linker (5'-GATCGGATCC-3') was inserted at the $B a m H I$ site to adjust the reading frame of the final construction. Finally, a BamHI-Sall fragment was cloned into pMA424. The junctions of all constructions were verified by sequence analysis. The fusion proteins stopped at the end of the STE12 sequence except in the following constructions: pGAL4STE $12_{1-473}$ (16 additional amino acids), pGAL4-STE12 $2_{1-215}(8$ additional amino acids), and pGAL-STE12 $214-473$ ( 16 additional amino acids). Plasmids were transformed into yeast by the lithium chloride method (Ito et al. 1983).

\section{Production of anti-STE12 antiserum}

The plasmid pYE contains a bacteriophage T7 promoter with the STE12-coding region under its control. The STE12-coding region was truncated by removing an $\mathrm{XbaI}-\mathrm{HindIII}$ fragment, resulting in the expression of just the first 215 amino acids of STE12. This plasmid was transformed into Escherichia coli strain BL21 (DE3), and the STE12 fragment was expressed after IPTG induction (Studier and Moffatt 1986). Induced cells were lysed by French press, and the lysates were fractionated on $12.5 \%$ SDS-polyacrylamide gels. The gels were stained with Coomassie blue, and the slices containing the STE12 fragment were cut out and the gel slice was crushed in $0.13 \mathrm{M} \mathrm{NaCl}, 10$ mM sodium phosphate ( $\mathrm{pH} 7.2$ ), to elute the fragment. This fragment was used to immunize rabbits at Cocalico, Inc. (Reamstown, PA|.

\section{Labeling and immunoprecipitation}

Procedures used for labeling and immunoprecipitation were modified from Hochstrasser and Varshavsky (1990). For ${ }^{35}$ S-labeling, cells were grown in $5 \mathrm{ml}$ of SRaf-histidine to an $\mathrm{OD}_{600}$ of $\sim 0.5$. The cells were harvested by centrifugation, washed three times with $1 \mathrm{ml}$ of SD (no supplements), and resuspended in $300 \mu \mathrm{l}$ of $50 \mathrm{mM} \mathrm{NaPO}_{4}$ (pH 7.5)/0.5\% glucose. The cells were incubated at $30^{\circ} \mathrm{C}$ for $15 \mathrm{~min}, 150 \mu \mathrm{Ci}$ of ${ }^{35} \mathrm{~S}$-labeled amino acids [either Expre ${ }^{35} \mathrm{~S}^{35} \mathrm{~S}$ (NEN) or Tran ${ }^{35}$ SLabel (ICN)] was added, and cells were incubated for an additional $10 \mathrm{~min}$. For labeling in the presence of $\alpha$-factor, cells were resuspended in $600 \mu$ l of $\mathrm{NaPO}_{4} /$ glucose and incubated at $30^{\circ} \mathrm{C}$ for $5 \mathrm{~min}, \alpha$-factor was added to a final concentration of $0.7 \mu \mathrm{M}$, incubation was continued for an additional $10 \mathrm{~min}$, and label was added as above. Following incubation with label, cells were pelleted and resuspended in $0.5 \mathrm{ml}$ of buffer A complete, 0.3 gram of glass beads was added, and the cells were lysed by vigorously vortexing for $3 \mathrm{~min}$, followed by boiling for $3 \mathrm{~min}$. Cells and cell debris were removed by centrifugation, and the supernatants were used for immunoprecipitations. Buffer A consisted of $50 \mathrm{~mm}$ Tris- $\mathrm{Cl} / \mathrm{pH}$ 
$8.0 \mid, 150 \mathrm{~mm} \mathrm{NaCl}, 5 \mathrm{~mm}$ EDTA, and 1\% Triton X-100. Buffer A complete contained the following additions: $20 \mu \mathrm{g} / \mathrm{ml}$ of pepstatin, $2 \mu \mathrm{g} / \mathrm{ml}$ of chymostatin, $20 \mu \mathrm{g} / \mathrm{ml}$ of leupeptin, $0.5 \mathrm{mM}$ PMSF, $50 \mathrm{~mm} 2$-mercaptoethanol, and $0.5 \%$ SDS.

For ${ }^{32} \mathrm{P}$-labeling, cells were grown overnight in modified Wickerham's media with raffinose and amino acids, supplemented with $100 \mu \mathrm{M}$ sodium phosphate $(\mathrm{pH} 7.5)$. The culture was diluted into $5 \mathrm{ml}$ of the above media without phosphate and grown to an $\mathrm{OD}_{600}$ of $\sim 0.5$. Cells were harvested by centrifugation, washed three times with $10 \mathrm{~mm}$ Tris- $\mathrm{Cl}(\mathrm{pH} 8.0) / 1 \mathrm{~mm}$ EDTA, and resuspended in $300 \mu \mathrm{l}$ of Wickerham salts/0.5\% glucose. Resuspended cells were incubated at $30^{\circ} \mathrm{C}$ for $15 \mathrm{~min}$, $250 \mu \mathrm{Ci}$ of $\mathrm{H}_{3}{ }^{32} \mathrm{PO}_{4}$ was added, and the cells were incubated for $60 \mathrm{~min}$. For labeling in the presence of pheromone, $\alpha$-factor was added to a final concentration of $0.7 \mu \mathrm{M}$ for the last $15 \mathrm{~min}$ of labeling. The cells were pelleted and lysed as described above.

For immunoprecipitations, equal amounts of TCA-precipitable counts (generally $1 \times 10^{6}$ to $2 \times 10^{6} \mathrm{cpm}$ ) were added to buffer $\mathrm{A}$ in a total volume of $400 \mu \mathrm{l}$. Rabbit antiserum against STE12 (amino acids 1-215) or GAL4 (amino acids 1-147 or 1881; gifts of P. Silver and L. Mylin/ was added, and the reactions were incubated at $4^{\circ} \mathrm{C}$ for $2 \mathrm{hr}$. Protein A-Sepharose (Sigma) was added, and the reactions were incubated at $30^{\circ} \mathrm{C}$ for an additional $30 \mathrm{~min}$. The immunoprecipitates were collected by centrifugation and washed three times with buffer A containing $0.1 \%$ SDS. The washed precipitates were resuspended in $25 \mu \mathrm{l}$ of $2 \times$ sample buffer (Laemmli 1970), boiled for $3 \mathrm{~min}$, and separated on a $6 \%$ SDS-polyacrylamide gel. Gels were fixed, washed with $1 \mathrm{M}$ sodium salicylate for $30 \mathrm{~min}$, dried, and exposed to Kodak X-AR5 film at $-70^{\circ} \mathrm{C}$.

\section{Phosphatase treatment of immunoprecipitates}

Samples to be treated with phosphatase were labeled and immunoprecipitated as described above. The washed immunoprecipitates were resuspended in $50 \mu \mathrm{l}$ of $50 \mathrm{~mm} \mathrm{Na}$ acetate (pH 5.4) and 0.5 units of potato acid phosphatase (Boehringer Mannheim Biochemicals) and incubated at $37^{\circ} \mathrm{C}$ for $30 \mathrm{~min}$. Where indicated, $25 \mathrm{mM} \mathrm{NaPO}_{4}(\mathrm{pH} 7.5)$ and $100 \mathrm{mM} \mathrm{Na}_{2} \mathrm{MoO}_{4}$ were added to specifically inhibit the phosphatase (Verjee 1969).

\section{Time course of $\alpha$-factor treatment}

Cells were grown in $10 \mathrm{ml}$ of SRaf-histidine to an $\mathrm{OD}_{600}$ of $\sim 0.5$, harvested by centrifugation, and washed three times with SD (no supplements). The cells were resuspended in $1 \mathrm{ml}$ of $\mathrm{NaPO}_{4} /$ glucose and incubated at $30^{\circ} \mathrm{C}$ for $15 \mathrm{~min}$. Then, 750 $\mu \mathrm{Ci}$ of ${ }^{35} \mathrm{~S}$-labeled amino acids were added, and cells were incubated for $5 \mathrm{~min}$. $\alpha$-Factor was added to a final concentration of $0.7 \mu \mathrm{M}$, and $0.2-\mathrm{ml}$ aliquots were removed after $0,1,2.5$, and 5 min. The aliquots were added to an equal volume of buffer $A$ complete and 0.3 grams of glass beads, immediately boiled for 3 $\mathrm{min}$, and vortexed vigorously for $3 \mathrm{~min}$. The lysate was clarified by centrifugation, and the supernatant was immunoprecipitated as described above.

\section{Cycloheximide treatment}

Cells were grown and labeled with ${ }^{35} \mathrm{~S}$ as described above with the following changes. The cells were labeled for $5 \mathrm{~min}$, and, where indicated, cycloheximide was added to a final concentration of $100 \mu \mathrm{g} / \mathrm{ml}$ and incubation continued for $5 \mathrm{~min}$. $\alpha$-Factor was added where indicated, and incubation was continued for an additional $5 \mathrm{~min}$. The cells were then lysed and immunoprecipitated as described. The inhibition of translation by cycloheximide was confirmed by removing $2-\mu l$ aliquots immedi- ately before the addition of cycloheximide and after $5 \mathrm{~min}$ and adding the aliquots to $200 \mu \mathrm{l}$ of $10 \%$ TCA and measuring the precipitable radioactivity. The amount of TCA-precipitable radioactivity continued to increase in cultures that did not receive cycloheximide but remained essentially unchanged in cultures that received cycloheximide.

\section{$\beta$-Galactosidase assays}

$\beta$-Galactosidase activity was assayed as described previously (Dolan and Fields 1990). The cells were grown in SGGE-histidine, and, where indicated, $\alpha$-factor was added to a final concentration of $0.7 \mu \mathrm{M}$ and cells were incubated at $30^{\circ} \mathrm{C}$ for $2 \mathrm{hr}$ prior to being assayed.

\section{Gel mobility-shift assay}

Preparation of extracts for gel shifts and the gel-shift procedure was as described previously, using as probe a 209-bp fragment of the MFA2 gene (Dolan et al. 1989). The strain was EG123 carrying the plasmid $\mathrm{pSY}$.

\section{Acknowledgments}

We thank Larry Mylin and Pam Silver for antibodies and Michael Gilman and Joseph Lipsick for comments on the manuscript. This work was supported by grants from the National Science Foundation (DMB 8916410), National Cancer Institute (5-T32-CA09176), Procter and Gamble Company, and the New York State Science and Technology Foundation.

The publication costs of this article were defrayed in part by payment of page charges. This article must therefore be hereby marked "advertisement" in accordance with 18 USC section 1734 solely to indicate this fact.

\section{References}

Bender, A. and G.F. Sprague Jr. 1986. Yeast peptide pheromones, a-factor and $\alpha$-factor, activate a common response mechanism in their target cells. Cell 47: 929-937.

Dietzel, C. and J. Kurjan. 1987. The yeast SCG1 gene: A G $_{\alpha}$-like protein implicated in the a- and $\alpha$-factor response pathway. Cell 50: 1001-1010.

Dolan, J.W. and S. Fields. 1990. Overproduction of the yeast STE12 protein leads to constitutive transcriptional induction. Genes \& Dev. 4: 492-502.

Dolan, J.W., C. Kirkman, and S. Fields. 1989. The yeast STE12 protein binds to the DNA sequence mediating pheromone induction. Proc. Natl. Acad. Sci. 86: 5703-5707.

Elion, E.A., P.L. Grisafi, and G.R. Fink. 1990. FUS3 encodes a cdc2 ${ }^{+} / \mathrm{CDC} 28$-related kinase required for the transition from mitosis into conjugation. Cell 60: 649-664.

Errede, B. and G. Ammerer. 1989. STE12, a protein involved in cell-type-specific transcription and signal transduction in yeast is part of protein-DNA complexes. Genes \& Dev. 3: $1349-1361$.

Fields, S. 1990. Pheromone response in yeast. Trends Biochem. Sci. 15: 270-273.

Fields, S. and I. Herskowitz. 1985. The yeast STE12 product is required for expression of two sets of cell-type-specific genes. Cell 42: 923-930.

Fields, S. and O. Song. 1989. A novel genetic system to detect protein-protein interactions. Nature 340: 245-246.

Fields, S., D.T. Chaleff, and G.F. Sprague Jr. 1988. Yeast STE7, $S T E 11$ and STE12 genes are required for expression of celltype-specific genes. Mol. Cell. Biol. 8: 551-556. 
Ghosh, S. and D. Baltimore. 1990. Activation in vitro of NF-kB by phosphorylation of its inhibitor ІкB. Nature 344: 678682.

Gill, G. and M. Ptashne. 1987. Mutants of GAL4 protein altered in an activation function. Cell 51: 121-126.

Hagen, D.C. and G.F. Sprague Jr. 1984. Induction of the yeast $\alpha$-specific STE3 gene by the peptide pheromone a-factor. $J$. Mol. Biol. 178: 835-852.

Hartig, A., J. Holly, G. Saari, and V.L MacKay. 1986. Multiple regulation of $S T E 2$, a mating-type-specific gene of Saccharomyces cerevisiae. Mol. Cell. Biol. 6: 2100-2114.

Hartwell, L. 1980. Mutants of Saccharomyces cerevisiae unresponsive to cell division control by polypeptide mating hormone. J. Cell Biol. 85: 811-822.

Herskowitz, I. 1989. A regulatory hierarchy for cell specialization in yeast. Nature 342: 749-757.

Hochstrasser, M. and A. Varshavsky. 1990. In vivo degradation of a transcriptional regulator: The yeast $\alpha 2$ repressor. Cell 61: 697-708.

Hope, I.A. and K. Struhl. 1986. Functional dissection of a eukaryotic transcriptional activator protein, GCN4 of yeast. Cell 46: 885-894.

Ito, H., Y. Fukuda, K. Murata, and A. Kimura. 1983. Transformation of intact yeast cells treated with alkali cations. $I$. Bacteriol. 153: 163-168.

Jahng, K.-Y., J. Ferguson, and S.I. Reed. 1988. Mutations in a gene encoding the $\alpha$ subunit of a Saccharomyces cerevisiae $\mathrm{G}$ protein indicate a role in mating pheromone signaling. Mol. Cell. Biol. 8: 2484-2493.

Keegan, L., G. Gill, and M. Ptashne. 1986. Separation of DNA binding from the transcription-activating function of a eukaryotic regulatory protein. Science 231: 699-704.

Laemmli, U. 1970. Cleavage of structural proteins during the assembly of the head of bacteriophage T4. Nature 227: 680 685.

Ma, J. and M. Ptashne. 1987. Deletion analysis of GAL4 defines two transcriptional activating segments. Cell 48: 847-853.

Manak, J.R., N. de Bisschop, R.M. Kris, and R. Prywes. 1990. Casein kinase Il enhances the DNA binding activity of serum response factor. Genes \& Dev. 4: 955-967.

McCaffrey, G., F.J. Clay, K. Kelsay, and G.F. Sprague Jr. 1987. Identification and regulation of a gene required for cell fusion during mating of the yeast Saccharomyces cerevisiae. Mol. Cell. Biol. 7: 2680-2690.

McVey, D., L. Brizuela, I. Mohr, D.R. Marshak, Y. Gluzman, and D. Beach. 1989. Phosphorylation of large tumour antigen by cdc2 stimulates SV40 DNA replication. Nature 341: 503507.

Mermod, N., E.A. O'Neill, T.J. Kelly, and R. Tiian. 1989. The proline-rich transcriptional activator of CTF/NF-I is distinct from the replication and DNA binding domain. Cell 58: $741-753$.

Miller, J.H. 1972. Experiments in molecular genetics. Cold Spring Harbor Laboratory, Cold Spring Harbor, New York.

Mitchell, P.J. and R. Tjian. 1989. Transcriptional regulation in mammalian cells by sequence-specific DNA binding proteins. Science 245: 371-378.

Miyajima, I., M. Nakafuku, N. Nakayama, C. Brenner, A. Miyajima, K. Kalbuchi, K. Arai, Y. Kaziro, and K. Matsumoto. 1987. GPA1, a haploid-specific essential gene, encodes a yeast homolog of mammalian $G$ protein which may be involved in mating factor signal transduction. Cell 50: $1011-$ 1019.

Moore, S.A. 1983. Comparison of dose-response curves for $\alpha$-factor-induced cell division arrest, agglutination, and projection formation of yeast cells. J. Biol. Chem. 258: 13849
13856.

Mylin, L.M., J.P. Bhat, and J.E. Hopper. 1989. Regulated phosphorylation and dephosphorylation of GAL4, a transcriptional activator. Genes \& Dev. 3: 1157-1165.

Mylin, L.M., M. Johnston, and J.E. Hopper. 1990. Phosphorylated forms of GAL4 are correlated with ability to activate transcription. Mol. Cell. Biol. 10: 4623-4629.

Nakayama, N., A. Miyajima, and K. Arai. 1987. Common signal transduction system shared by STE2 and STE3 in haploid cells of Saccharomyces cerevisiae: Autocrine cell-cycle arrest results from forced expression of STE2. EMBO I. 6: 249254.

Nasmyth, K., G. Adolf, D. Lydall, and A. Seddon. 1990. The identification of a second cell cycle control on the HO promoter in yeast: Cell cycle regulation of SWI5 nuclear entry. Cell 62: 631-647.

Rhodes, N., L. Connell, and B. Errede. 1990. STE 11 is a protein kinase required for cell-type-specific transcription and signal transduction in yeast. Genes \& Dev. 4: 1862-1874.

Sherman, F., G.R. Fink, and J.B. Hicks. 1986. Methods in yeast genetics. Cold Spring Harbor Laboratory, Cold Spring Harbor, New York.

Siliciano, P.G. and K. Tatchell. 1984. Transcription and regulatory signals at the mating type locus in yeast. Cell 37: 969978.

Sorger, P.K. and H.R.B. Pelham. 1988. Yeast heat shock factor is an essential DNA-binding protein that exhibits temperature-dependent phosphorylation. Cell 54: 855-864.

Sorger, P.K., M.J. Lewis, and H.R.B. Pelham. 1987. Heat shock factor is regulated differently in yeast and HeLa cells. Nature 329: 81-84.

Stetler, G.L. and J. Thorner. 1984. Molecular cloning of hormone-responsive genes from the yeast Saccharomyces cerevisiae. Proc. Natl. Acad. Sci. 81: 1144-1148.

Studier, F.W. and B.A. Moffatt. 1986. Use of bacteriophage T7 RNA polymerase to direct selective high-level expression of cloned genes. J. Mol. Biol. 189: 113-130.

Teague, M.A., D.T. Chaleff, and B. Errede. 1986. Nucleotide sequence of the yeast regulatory gene $S T E 7$ predicts a protein homologous to protein kinases. Proc. Natl. Acad. Sci. 83: $7371-7375$.

Theill, L.E., J.-L. Castrillo, D. Wu, and M. Karin. 1989. Dissection of functional domains of the pituitary-specific transcription factor GHF-1. Nature 342: 945-948.

Trueheart, J., J.D. Boeke, and G.R. Fink. 1987. Two genes required for cell fusion during yeast conjugation: Evidence for a pheromone-induced surface protein. Mol. Cell. Biol. 7: 2316-2328.

Verjee, Z.H.M. 1969. Isolation of three acid phosphatases from wheat germ. Eur. I. Biochem. 9: 439-444.

Weston, K. and J.M. Bishop. 1989. Transcriptional activation by the $v-m y b$ oncogene and its cellular progenitor, $c-m y b$. Cell 58: $85-93$.

Whiteway, M., L. Hougan, D. Dignard, D.Y. Thomas, L. Bell, G.C. Saari, F.J. Grant, P. O'Hara, and V.L. MacKay. 1989. The STE4 and STE18 genes of yeast encode potential $\beta$ and $\gamma$ subunits of the mating factor receptor-coupled $G$ protein. Cell 56: 467-477.

Wickerham, L.J. 1946. A critical evaluation of the nitrogen assimilation tests commonly used in the classification of yeasts. J. Bacteriol. 52: 293-301.

Yamamoto, K.K., G.A. Gonzalez, P. Menzel, J. Rivier, and M.R. Montminy. 1990. Characterization of a bipartite activator domain in transcription factor CREB. Cell 60: 611-617. 


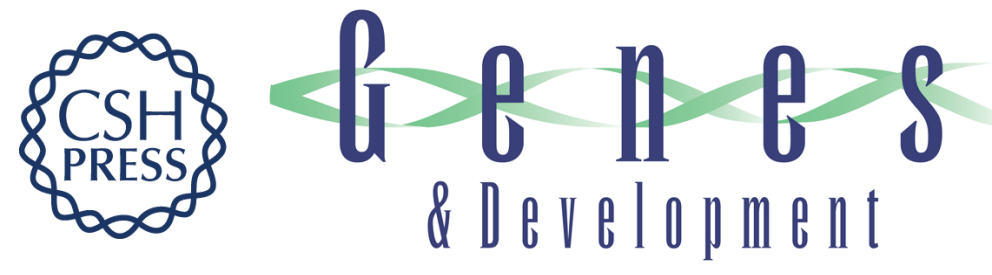

\section{Pheromone-dependent phosphorylation of the yeast STE12 protein correlates with transcriptional activation.}

D Song, J W Dolan, Y L Yuan, et al.

Genes Dev. 1991, 5:

Access the most recent version at doi:10.1101/gad.5.5.741

References This article cites 48 articles, 19 of which can be accessed free at:

http://genesdev.cshlp.org/content/5/5/741.full.html\#ref-list-1

License

Email Alerting

Service

Receive free email alerts when new articles cite this article - sign up in the box at the top right corner of the article or click here.

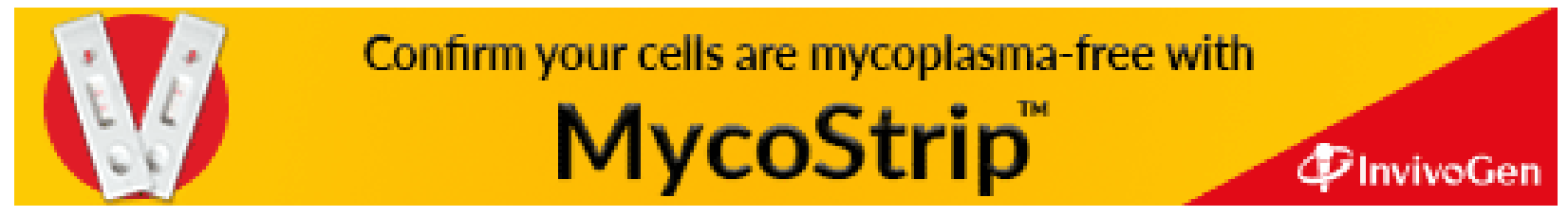

